\title{
DETERMINING THE LEVELS OF VITAMIN D AND PARATHYROID HORMONE IN PATIENTS ON HEMODIALYSIS
}

\author{
R. Mihaylov', B. Pencheva', D. Stoeva ${ }^{3}$, N. Marinova', S. Krivoshiev² and G. Michailov² \\ 'Medical Laboratory „Ramus" - Sofia, Bulgaria \\ ${ }^{2}$ Clinic of Haemodialysis, University Hospital "Tsarista Yoanna - ISUL" - Sofia, Bulgaria \\ ${ }^{3}$ Clinical Laboratory, University Hospital "Tsarista Yoanna - ISUL" - Sofia, Bulgaria
}

Summary. Vitamin D deficiency is fequently observed in chronic kidney disease. We conducted this study to determine the concentration of the above-mentioned parameters and the correlation between them in order to optimize therapy with vitamin $\mathrm{D}$ in patients with end-stage renal disease (ESRD) on hemodialysis. In 53 patients on hemodialysis due to ESRD, vitamin D [Calcidiol $(25(\mathrm{OH}) \mathrm{D}$ ], parathyroid hormone (PTH), calcium, phosphorus, albuminuria, albumin:creatinine ratio (ACR) and other parameters have been followed up. Analysis of the levels of vitamin D has been carried out by High Performance Liquid Chromatography (HPLC), the PTH is determined by the system Centaur XP, Siemens Diagnostic, Electro-chemiluminescence immunoassay (ECLIA), and for albumin in urine we used immunological method [Miltigent microalbumin assay (Abbott Laboratories Diagnostics). We found out deficiency and insufficiency of vitamin $\mathrm{D}$ in $56.6 \%$ and $37.7 \%$, as well as average 4.5 times increase in the PTH, hyperphosphatemia, hypocalcemia, albuminuria (A2 or A3), over 10 times increase in the ACR, secondary hyperparathyroidism. We registered a negative correlation between vitamin $\mathrm{D}$ and $\mathrm{PTH}$. We confirmed the increase in creatinine and cystatin $C$ in the patients on hemodialysis. There are few literature data for patients on hemodialysis, however, regarding the extent of the vitamin deficiency and its relationship with PTH, albuminuria, calcium, phosphorus, etc. Our data have indicated that patients on hemodialysis due to ESRD are associated with high incidence of vitamin $D$ insufficiency or deficiency.

Key words: vitamin D, end-stage renal disease, parathyroid hormone, albuminuria, albumin: creatinine ratio in the urine, calcium, phosphorus 


\section{INTRODUCTION}

$\mathrm{R}$ ecently, vitamin $D$ has been the subject of many studies because of its important endocrine, paracrine and immune functions [1, 2, 3]. Healthy kidneys are rich in vitamin $D$ receptors and play an important role in converting the vitamin into its active form, calcitriol. Thus, there is a balance of calcium and phosphorus in the body through their controlled absorption from food and regulation from the parathyroid hormone (PTH) [4, 5]. Many patients with end-stage renal disease (ESRD) are unable to synthesize the active form of vitamin $D$ and they are at risk of secondary hyperparathyroidism $[1,5]$. The latter can lead to renal osteodystrophy, mineral changes, deposition of calcium in the vessels and soft tissue and other $[6,7]$. Patients with ESRD exhibit reduced activity of the enzyme a-1- hydroxylase (CYP27B1) in the kidneys, which converts 25-hydroxy vitamin D [25(OH)D] into its more active form 1,25-dihydroxyvitamin $D[(1,25(\mathrm{OH}) 2 \mathrm{D})]$. Another reason for hypovitaminosis is the loss of vitamin $\mathrm{D}$ transport proteins through the glomerulus [6, 8]. This requires patients to be treated with supplement vitamin D. The main objective marker of ESRD - albuminuria shows reduction when taking vitamin D. Although vitamin $\mathrm{D}$ can be converted into an active form outside the kidneys, including prostate, breasts, colon and macrophages, it is difficult to compensate hypovitaminosis in ESRD patients on hemodialysis [9]. The lack of data on vitamin D in our country (including deficiency, insufficiency or sufficiency), PTH, calcium, phosphorus and albuminuria in patients on hemodialysis and the relationship between them made us conduct this study.

\section{AIM}

The aim of this study was to monitor the levels of vitamin D, PTH, calcium, phosphorus, albuminuria, albumin:creatinine ratio (ACR) in patients on hemodialysis due to ESRD and to indicate directions for further treatment of patients.

\section{MATERIAL AND METHODS}

We followed up 53 patients on hemodialysis due to ESRD: 29 male $(54.7 \%)$, aged between 34 and 74 (mean age 50.2); 24 female (45.3\%), aged 30 to 84 (mean age 55.3). We examined the following parameters: $25(\mathrm{OH}) \mathrm{D}$, PTH, calcium, phosphorus, glucose, cystatin $\mathrm{C}$, creatinine, uric acid in serum, urine calcium, creatinine in urine, complete blood count, ACR, calcium/creatinine ratio in urine. Analysis of the levels of vitamin D has been carried out by High Performance Liquid Chromatography (HPLC), the PTH is determined by the system Centaur XP, Siemens Diagnostic, Electro-chemiluminescence immunoassay (ECLIA), and for albumin in urine we used immunological method [Miltigent microalbumin assay (Abbott Laboratories Diagnostics)]. For the statistical analysis we used Excel ANOVA. 


\section{RESULTS}

Characteristics of the patients included in the study are presented in Table 1.

Table 1. Characteristics of the patients

\begin{tabular}{|l|l|}
\hline Characteristics & Number, $\%$ or range \\
\hline Total & $53,100 \%$ \\
\hline Male & $29,54.7 \%$ \\
\hline Female & $24,45.3 \%$ \\
\hline Male - age (years) & $50.2(34-74)$ \\
\hline Female - age (years) & $55.3(30-84)$ \\
\hline Duration of the disease (years) & $16.3(1-30)$ \\
\hline
\end{tabular}

Table 2. Analysis of variance of the obtained results

\begin{tabular}{|l|l|l|l|}
\hline Parameter & Mean value & SD & CV\% \\
\hline PTH $(\mathrm{pg} / \mathrm{ml})$ & 330.00 & 438.03 & 132.73 \\
\hline Vitamin D $(\mathrm{ng} / \mathrm{ml})$ & 19.08 & 9.43 & 49.43 \\
\hline Cystatin C $(\mathrm{mg} / \mathrm{l})$ & 5.33 & 0.98 & 18.47 \\
\hline ACR $(\mathrm{mmol} / \mathrm{l})$ & 152.36 & 202.16 & 132.68 \\
\hline Ca in urine $(\mathrm{mmol} / \mathrm{l})$ & 0.76 & 0.19 & 25.10 \\
\hline Ca in serum $(\mathrm{mmol} / \mathrm{l})$ & 2.05 & 0.17 & $\mathrm{~N} / \mathrm{A}$ \\
\hline Ca/Creat. in urine & 99.44 & 93.38 & 93.91 \\
\hline Inorg. phos. $(\mathrm{mmo} / /)$ & 1.69 & 1.97 & $\mathrm{~N} / \mathrm{A}$ \\
\hline Creatinine in serum $(\mu \mathrm{mol} / \mathrm{l})$ & 831.05 & 183.8 & 22.12 \\
\hline Glucose in serum $(\mu \mathrm{mol} / \mathrm{l})$ & 6.33 & 3.28 & 51.91 \\
\hline Uric acid $(\mu \mathrm{mol} / \mathrm{l})$ & 400.51 & 98.91 & 24.67 \\
\hline Hemoglobin $(\mathrm{g} / \mathrm{l})$ & 104.34 & 13.52 & 12.96 \\
\hline
\end{tabular}

The obtained results reveal that the average value of vitamin $D$ was in the scope of hypovitaminosis $(19,08 \pm 9.43)$, while that of PTH was quite above the upper reference limit (4.5 times increase above the upper reference limit $(72 \mathrm{pg} / \mathrm{ml})$. As expected, patients had strong hypercreatininemia (831.05 \pm 183.8$)$ and hypercystatinemia (5.33 \pm 0.98$)$, expressed albuminuria (A2 and A3) and increased more than 10 times ACR in urine $(152,36 \pm 202.16)$. We registered mild hypocalcaemia $(2.05 \pm 0.17)$, mild hyperphosphatemia $(1,69 \pm 1,97)$ and mild hyperparathyroidism [PTH $(\mathrm{pg} / \mathrm{ml}) 330.00 \pm 438.03]$. We have registered secondary hyperparathyroidism (increased PTH and phosphate and decreased calcium) in $71.6 \%$ of the patients.

Hyperuricemia (400.51 \pm 98.91) and anemic syndrome (Hemoglobin $104.34 \pm$ 13.52) were mild. As it can be seen from the results presented (on Tabl. 3 and Fig. 1 ) the hypovitaminosis in patients was as follows: no patients with severe deficiency $(<10 \mathrm{ng} / \mathrm{ml}) ; 30$ patients $(56.6 \%)$ were with deficiency $(10.1-20 \mathrm{ng} / \mathrm{ml}) ; 20$ patients $(37.7 \%)$ were with insufficiency $(20.1-30 \mathrm{ng} / \mathrm{ml})$ and only 3 patients $(5.66 \%)$ were with vitamin D sufficiency $(>30 \mathrm{ng} / \mathrm{ml}) .41$ of the patients $(77.4 \%)$ were with PTH 
over $72 \mathrm{pg} / \mathrm{ml}$ and 38 (71.6\%) with PTH over $90 \mathrm{pg} / \mathrm{ml}$ (cutoff value accepted by us). Data from correlations between the parameters are presented in Table 4. We have observed weak or moderate negative linear correlation of vitamin $D$ with calcium in serum $(r=-0.074)$, with duration of the disease $(r=-0.105)$, with PTH $(r=-0.114)$, with calcium in urine $(r=-0.212)$ and with individual parameters (gender and uric acid) there was weak positive linear correlation $(r=0.096$ and $r=0.163)$.

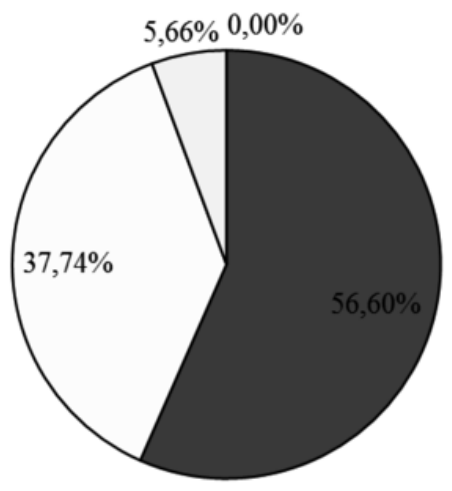

$\square$ Severe deficiency
$\square$ Deficiency
$\square$ Insufficiency
$\square$ Sufficiency

Fig. 1. Distribution of concentrations of 25-hydroxy vitamin D

Table 3. Concentration of Vitamin D

\begin{tabular}{|l|l|l|}
\hline Concentration of Vitamin D & Number of patients & Percent (\%) of all patients \\
\hline Severe deficiency < $10 \mathrm{ng} / \mathrm{ml}$ & 0 & $0.0 \%$ \\
\hline Deficiency from 10.1 to $20.0 \mathrm{ng} / \mathrm{ml}$ & 30 & $56,6 \%$ \\
\hline Insufficiency from 20.1 to $30.0 \mathrm{ng} / \mathrm{ml}$ & 20 & $37,74 \%$ \\
\hline Sufficiency $>30 \mathrm{ng} / \mathrm{ml}$ & 3 & $5,66 \%$ \\
\hline
\end{tabular}

Table 4. Correlation of vitamin D with individual parameters

\begin{tabular}{|l|l|}
\hline Individual parameters & $\mathbf{R}$ (Coefficient of correlation) \\
\hline Gender & 0,096793257 \\
\hline Weight & $-0,140463132$ \\
\hline Age & $-0,380257457$ \\
\hline Duration of the disease & $-0,104599687$ \\
\hline Hemoglobin & $-0,439056889$ \\
\hline Calcium in serum & $-0,074145858$ \\
\hline Uric acid & 0,16383389 \\
\hline PTH - parathyroid hormone & $-0,114465746$ \\
\hline Calcium / creatinine in urine & $-0,212170055$ \\
\hline
\end{tabular}




\section{DISCUSSION}

Recently, the growing evidence has suggested that vitamin $D$ has important endocrine, autocrine and immune functions $[1,2,3]$. Healthy kidneys have an important function to maintain the balance between vitamin D, PTH, calcium and phosphorus. Patients with ESRD demonstrated reduced activity of the enzyme alpha-1-hydroxylase (CYP27B1) in the kidneys, which converts 25-hydroxyvitamin D $(25(25)(\mathrm{OH})$ $D$ ) into its more active form 1, 25-dihydroxyvitamin D (1,25 (OH) 2D); increased loss of vitamin $D$ transport proteins, and reduced expression of the vitamin $D$ receptors $[1,4,5]$. The active form of vitamin $D$ has only 8-12 hours half-life in plasma and responds dynamically to changes in the concentration of calcium and phosphate. The presence of extra renal alpha-1-hydroxylase in other organs (prostate, breasts, colon and macrophages) is unable to compensate for the reduced enzymatic activity in the kidneys but is particularly necessary for the immune system and the synthesis of the antimicrobial peptide cathelicidin [4, 9]. This enzyme deficiency correlates with an increase in PTH and phosphate and decrease in vitamin D and calcium [10]. It is expected that these changes are especially pronounced in patients on hemodialysis. There are few literature data for patients on hemodialysis, however, regarding the extent of the vitamin deficiency and its relationship with PTH, albuminuria, calcium, phosphorus $[4,5,6,7]$. Increased PTH and hyperphosphatemia have been recently identified as risk factors for mortality in patients on hemodialysis [11]. Serum 25$\mathrm{OH}-\mathrm{D}$ is a generally accepted parameter of vitamin D status, but has no universal reference level. This study demonstrated mineral imbalance, expressed vitamin D hypovitaminosis and secondary hyperparathyroidism. We found out hypovitaminosis of vitamin D in 50 patients $(94.3 \%)$ and 30 patients (56.6\%) of them with a deficiency $(<20 \mathrm{ng} / \mathrm{ml})$ and 20 patients $(37,7 \%)$ of them with an insufficiency $(21-30 \mathrm{ng} / \mathrm{ml})$. We have no patients with severe deficiency $(<10 \mathrm{ng} / \mathrm{ml})$ and there are only 3 patients $(5,66 \%)$ without vitamin D hypovitaminosis $(>30 \mathrm{ng} / \mathrm{ml})$. Like other authors, we associated the observed hypovitaminosis with the reduced activity of the alpha-1-hydroxylase, mild expression of vitamin $D$ receptors and an increased loss of vitamin $D$ transport proteins $[12,13,14]$. It is known that active form of vitamin $D$ has only $8-12$ hours half-life and responds dynamically to changes in calcium and phosphorus [4]. Hypovitaminosis of vitamin $\mathrm{D}$, decreased calcium and increased phosphorus lead to secondary hyperparathyroidism $[3,5,6]$. We registered secondary hyperparathyroidism in $71.6 \%$ of the patients with average increase in PTH is over 4,5 times (see Tabl. 2), as 38 patients $(71,6 \%)$ are with PTH over $90 \mathrm{pg} / \mathrm{ml}$ (cut-off value accepted by us). In parallel to this we observed hyperphosphatemia $(\bar{x}=1,97 \pm 0.47)$, and mild hypocalcaemia $(\bar{x}=2.05 \pm 0.17)$. As expected the albuminuria was of type A2 or A3, and ACR was greatly increased (over 10 times) which probably leads to loss of proteins transporting vitamin D. Hypovitaminosis might be associated with a defect in the activation of the vitamin $D$ receptors, the absorption of the vitamin by the glomerular ultrafiltrate, as well as the activation or suppression of genes that support the mineral homeostasis and integrity of the skeleton in order to prevent secondary 
hyperparathyroidism, hypertension, disorders of the immune system, cardiovascular changes, and increased mortality [15, 16, 17]. According to literature data, nearly $80 \%$ of the patients who begin dialysis are with a level of vitamin $D<30 \mathrm{ng} / \mathrm{ml}$, while in patients in the final stage the percentage is more than $90-95 \%[3,12,17]$. The increased synthesis and secretion of PTH stimulates hypocalcemia, hyperphosphatemia and vitamin D deficiency [16, 17]. It is difficult to explain if hypocalcemia is not associated with the deposition of calcium in vessels and tissues in our patients, which is mentioned by other authors [3, 4, 9, 18-21].

\section{CONCLUSION}

Our results showed that in patients with ESRD on hemodialysis it is observed universal vitamin D deficiency $(56.6 \%)$ or insufficiency $(37.7 \%)$. Along with this, we registered up to 4,5 times increase in PTH, as well as an expression of secondary hyperparathyroidism and abnormal mineral metabolism (hypocalcemia with hyperphosphataemia). The established by us albuminuria A2 or A3 and highly increased ACR undoubtedly contributed to the expressed $D$ hypovitaminosis. We deem it is necessary that for patients on hemodialysis the concentration of vitamin D, PTH, albuminuria, ACR, calcium and phosphorus should be monitored in advance in order to optimize the intake of vitamin D.

\section{REFERENCES}

1. Abboud H, Henrich W.L. Stage IV Chronic Kidney Disease. - N Engl J Med. 362, 2010, № 1, 56-65.

2. KDIGO. Clinical practice guidelines for the diagnosis, evaluation, prevention and treatment of chronic kidney disease- mineral and bone disorder. - Kidney Int Suppl. 2009;113:S1-130.

3. Gonzalez EA, Sachdeva A, Oliver DA, Martin KJ. Vitamin D insufficiency and deficiency in chronic kidney disease: A single center observational study. - Am J Nephrol .24, 2004, № 3, 503-510.

4. Melamed M L, Thadhani R I. Vitamin D Therapy in Chronic Kidney Disease and End Stage Renal Disease. - Clin J Am Soc Nephrol. 7, 2012, № 2, 358-365.

5. Andress D L. Vitamin D in chronic kidney disease: A systemic role for selective vitamin $D$ receptor activation. - Kidney Int. 69, 2006, № 1, 33-43.

6. Bosworth C.R, Levin G, Robinson C. The serum 24,25- Dihydroxyvitamin D concentration, a marker of vitamin D catabolism, is reduced in chronic kidney disease. - Kidney Int., 82, 2012, № 5, 693-700.

7. Jean G, Granjon S, Zaoui E. Usefulness and feasibility of measuring ionized calcium in haemodialysis patients. - Clin Kidney J.8, 2015, № 4, 378-387.

8. Kandula P, Dobre M, Schold J.D, Vitamin D supplementation in chronic kidney disease: An systematic review and meta-analysis of bservational studies and randomized controlled trials. - Clin J Am Soc Nephrol. 6, 2011, № 1, 50-62.

9. Bhan I, Burnett-Bowie SA, Ye J. Clinical measures identify vitamin D deficiency in dialysis. - Clin J Am Soc Nephrol. 5, 2010, № 3, 460-467.

10. Jean G, Terrat J, Vanel T, et al. Daily oral 25 -hydroxycholecalciferol supplementation for vitamin D deficiency in haemodialysis patients :Effects on mineral metabolism and bone markers. - Nephrol Dial Transplant. 23, 2008, № 7, 3670-3676. 
11. Kim G, Choi B, Cha D. Serum calcium and phosphorus levels in patients undergoingmaintenance hemodialysis. - Kidney Res Clin Pract 33, 2014, № 1, 52-57.

12. Bansal B, Bansal S, Mithal A. Vitamin D deficiency in hemodialysis patients. - Indian J Endocrinol Metab. 16, 2012, № 2, 270-273.

13. Dusso A S, Tokumoto M. Defective renal maintenance of the vitamin D endocrine system impairs vitamin D renoprotection: a downward spiral in kidney disease. - Kidney Int. 79, 2011, № 4, 715-729.

14. Bhan K, Dobens D, Tamez H. Nutritional Vitamin D Supplementation in Dialysis: A Randomized Trial. - Clin J Am Soc Nephrol. 10, 2015, № 4, 611-619.

15. Rathod A, Bonny O, Guessous I. Association of Urinary Calcium Excretion with Serum Calcium and Vitamin D Levels. - Clin J Am Soc Nephrol . 10, 2015, № 3, 452-462.

16. 18. Díaz M, Deetjen J, Guinsburg A. Calcium, Phosphorus, PTH and Death Rates in a Large Sample of Dialysis Patients From Latin America. - Nephrol Dial Transplant. 26, 2011, № 6,1938-1947.

17. Micozkadioglu H, Ozelsancak R, Yildiz I, et al. Circadian rhythm of serum phosphate, calcium and parathyroid hormone levels in hemodialysis patients. - Clin Lab. 59, 2013, № 1-2,79-84.

18. Keyzer C.A, Heerspink H, Joosten M. Plasma. Vitamin D Level and Change in Albuminuria and eGFR According to Sodium Intake. - Clin J AmSoc Nepjhrol. 10, 2015, doi: 10.2215/CJN.03830415

19. Holick M.F, Binkley N.C, Bischoff-Ferrari HA et al. Evaluation, Treatment, and Prevention of Vitamin D Deficiency: An Endocrine Society Clinical Practice Guideline. - J Clin Endocrinol Metab.96, 2011, № 10,1911-30.

\section{Corresponding author:}

B. Pencheva, DM

Medical Laboratory "Ramus"

2-4 Angista St.

Bg - 1527 Sofia

tel. 02/943-1196

e-mail: blagovesta.pencheva@ramuslab.com 